\title{
Ahimsa (Noninjury) Revisited
}

\author{
Michael W. Fox \\ The Humane Society \\ of the United States
}

Paper given at the Jain Association in North America (JAINA) Convention, Pittsburgh, July 1993.

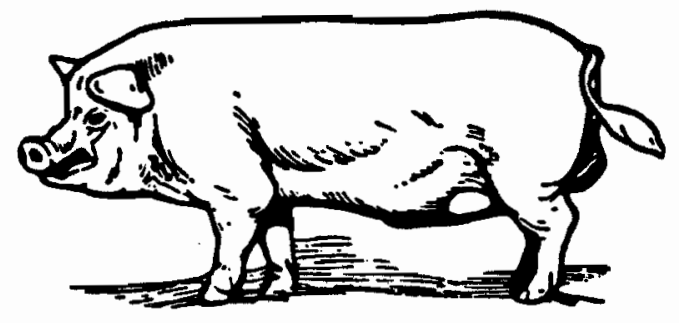

The ancient Sanskrit word ahimsa, meaning noninjury, is the doctrine of refraining from the harming of others. It is the central teaching of Jainism, Hinduism and Buddhism. As an ethical principle, we find it in the Judeo-Christian concept of the Golden Rule that holds that we should not do to others what we would not have them do to us. And it is implicit in the medical maxim "physician do no harm."

The doctrine of ahimsa is a call to ethical action. This active principle was termed satyagraha by Mahatma Gandhi-the power of compassionate action.

Actions that entail the helping of life need to be as carefully considered as those actions that entail the deliberate, unavoidable taking or harming of life. This is because our most altruistic actions can have harmful consequences to others if we do not follow the absolute mandate of considering the doctrine of ahimsa (or the Golden Rule). Because of the many cruel paradoxes that we face today, situational ethics are such that while we cannot live by the Golden Rule as an absolute, we absolutely must consider the Golden Rule prior to deciding upon any action. We should be mindful of the differences between unavoidable, natural (pervasive) suffering we see in nature and the often avoidable

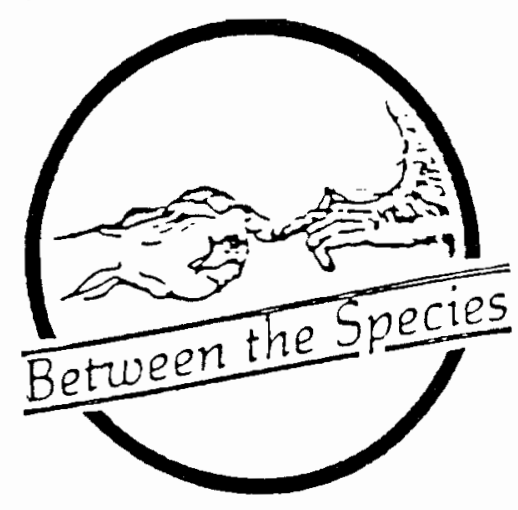

(human-caused) suffering, over which we do have considerable control.

The only absolute principle is to have reverence and respect for all life. This does not preclude the unavoidable harming or taking of life, since we cannot, in these times, live by the absolute ethic of ahimsa or the Golden Rule. We do, however, have the absolute responsibility to apply these ethical principles to govern ourselves for the good of all. For example, we regrettably must accept the humane destruction of "surplus" elephants to help preserve herd and habitat when there are no alternative solutions available, such as a method of birth control or more elephant habitat. Likewise animal shelters around the world engage in euthanizing millions of homeless cats and dogs. But in all such instances, humane alternatives must be sought for future application so as to avert the continuation of situations and circumstances incompatible with the doctrine of ahimsa.

The doctrine of ahimsa encompasses both human and nonhuman (plant and animal) life. It also embraces non-living entities such as lakes, swamps, and all natural ecosystems that can be harmed by various human activities that in turn may harm the animal and plant communities therein.

Some philosophers reason that since some animal species are more sensitive and intelligent than "lower" life forms, they have more "intrinsic" value. So they

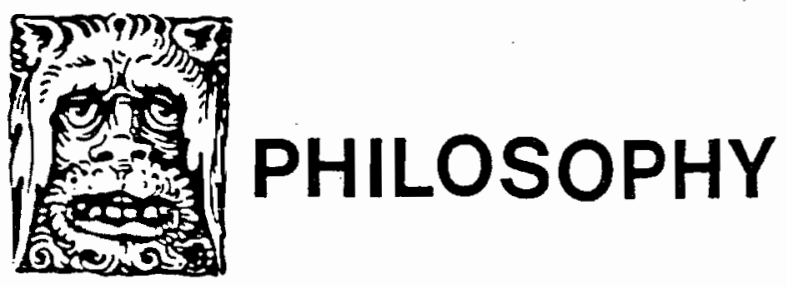


believe these animals (like elephants) should therefore receive more respect and protection because they have a higher degree of sentience than "lower" lifeforms (like worms and insects). I believe this line of thinking is anthropocentric and "speciesist." So-called "lower" life forms in healthy, natural ecosystems have great "extrinsic" value in their vital contribution to helping maintain the functional integrity of ecosystems-the "balance" of nature. For example, earthworms are soil makers, and various insects pollinate plants. In spite of their relatively low degree of sentience, these and other "lowly" creatures play a far more significant role than most humans in their contribution to the well-being of the natural world.

This doctrine of noninjury does not limit respect and compassion to living entities based upon their degree of sentience, but also includes non-sentient living (eco) systems within the scope of moral consideration and empathic concern, critics might argue that because it is so all embracing: Thus, the doctrine of ahimsa is an impractical and unrealistic ideal. Yet by virtue of its illimitable scope, it takes us beyond the polemicizing dualities of animal versus human rights and human interests versus environmental protection and nature conservation. It is surely from such an all encompassing ethical sensibility that we can best consider, rationally and sensitively, the rights and interests of the entire life community of the planet. This doctrine is the cornerstone of a just, humane and sustainable society. It is also enlightened self-interest, because when we harm others, including the environment, we inevitably harm ourselves.

This latter point leads us to a related principle of these Eastern religious teachings, namely, the law of karma. One's destiny is influenced by one's thoughts, words and actions. (What goes around, comes around.) The law of karma therefore recognizes that good will ultimately come to those who endeavor as best they can to live according to the doctrine of ahimsa. But this is no easy task when we are born into a culture where social discord and violence are endemic and contagious; where cruelty toward animals is condoned and institutionalized; and where the destruction of the natural world is economically rationalized and industrially sanctioned.

It takes great courage, commitment, and vigilance to live in accord with the doctrine of ahimsa in a culture whose values are antithetical to this compassionate ethic of noninjury. Yet the more we can disengage our lives from those forces that are responsible for so much suffering and destruction in the world today, and still enjoy productive and meaningful lives, the more society will change and become more humane, socially just and environmentally sustainable.

For example, we can disengage, as consumers, from supporting cruel factory-farming systems by not purchasing various animal products from such farms. We can also support organic farmers by selectively purchasing their produce, and buy various cosmetics and other consumables that have not been consumersafety tested on animals, and which contain no ingredients of animal origin.

But as predominantly urban-dwelling consumers, often employed in industry-related businesses that value economic growth and material profit over environmental and animal protection (and even over consumer protection and worker safety), there seems to be no escape: No alternative but to be part of a culture that is the antithesis of ahimsa.

There are, however, some choices that we are still free to make in accordance with the doctrine of ahimsa. And every choice that we make is a vote that will make a difference, like choosing to eat less meat or to become a vegetarian; to have a small, fuel-efficient car; to recycle household and office trash; to buy "cruelty-free" toiletries. The choices are many once we become more vigilant, informed and dedicated to live as best we can in gentler ways that cause less harm to others and the natural world.

Certainly we must exploit life in order to sustain our own. In natural ecosystems, one life supports another. The entire plant-animal food-chain reveals how interdependent each life form is and how each life gives as much as it takes so that ecological balance is preserved, and the system remains sustainable and selfrenewing.

We have been slow to apply these scientific findings and natural laws to modern agriculture and other industries. It is noteworthy that in every healthy (balanced) ecosystem, every life-form therein plays an integral role and even if it takes another's life, it still causes more good than harm to the life community within that system. But since the human species is less constrained than other creatures and has the powers of free-will and dominion to act outside of natural law, we must, for the good of the whole and for our own good, apply the guiding principle of ahimsa to help ensure that when we exercise these powers, we cause more good than harm to the life community. 
The cultural assimilation of the doctrine of ahimsa is the hallmark of a truly humane society. We have much work to do to help lay this foundation for such a society. That we will never enjoy it in this lifetime is no reason for us not to begin to build our own lives around the doctrine of ahimsa, for the good of all and for generations to come.

Animals have served many human needs over hundreds of thousands of years. They have variously provided us with food, shelter, social status, clothing, labor (as for draft work, pulling ploughs, carts and sleds), and have served loyally as companions and guards of home and livestock. Many animals, especially dogs, have heroically saved their human companions from accidental drowning or fire, being buried alive under an avalanche, or suffering under the burden of loneliness and depression.

Our demands upon animals have increased rather than decreased over the millennia as human society has become more industrialized, if not actually more civilized. Should we not forfeit any presumed entitlement over them so long as we continue to cause them any physical injury or psychological harm that could be avoided without resulting in any comparable injury or harm to ourselves? The following examples of widespread animal cruelty and suffering clearly illustrate that our power of dominion over them is being abused and that without concerted effort, contemporary society will continue its ethical and spiritual decline, and suffer the consequences.

The meat, eggs and dairy products we consume come mainly from animals raised in cruel factory farms where they are either stressed out and made susceptible to disease by extreme overcrowding in cages or pens, or are so confined alone in crates or stalls that they can neither walk nor turn around. Until these systems are changed to provide animals with environments that better meet their physical and psychological needs, we owe it to them not to support such inhumane production methods by eating less or no animal products from factory farms; by selectively purchasing produce from farmers and ranchers who have adopted less intensive and more humane methods of livestock and poultry production; or by becoming vegetarians.

Many other consumables, from household cleaners to cosmetics and other toiletries, have been safety-tested on animals, these laboratory tests often resulting in great suffering. Concerned consumers purchase products that are either clearly marked as not having been tested on animals, or buy old tried and true brands rather than "new and improved" products that have most likely been tested on animals. The suffering of animals for such trivial ends cannot be justified. Many compassionate consumers go one step further and boycott any products that contain animal ingredients, like perfumes that contain animal musk oil and soaps and cosmetics that contain animal fat (tallow) and oils.

Items of adornment, from fur coats to leather goods and jewelry made from various animal products are avoided by those who care for animals. Furs come from wild animals that are caught and suffer great anguish in steel jaw traps and snares: or from wild animals raised in small cages on fur farms where conditions are no better than on cruel factory farms. Other animal products come from rare and endangered wild animals that are killed merely for their ivory, skins or other body parts that are used to make jewelry and other accessoriesand even folk medicine in the Far East.

Various animals kept as companions or pets come from a commercial pet trade that all caring people boycott by adopting animals instead from the local animal shelter. Many purebred puppies for sale in pet stores come from "puppy mill" factory farms that are often as cruelly deplorable as livestock and poultry farm factories. Other more "exotic" pets, like parrots and other creatures caught in the wild, suffer high mortalities before they ever reach the pet shop. And they don't make good pets, since they have not been bred to adapt to captivity and to a domesticated existence.

Animals also suffer in the name of sport and entertainment. Such activities and events, like trophy hunting and sport fishing, rodeos, horse races, animal circuses, and roadside zoos, do not enjoy the support of those who have a vestige of empathy for animals wild and tame.

These examples affirm my contention that until all such abuses cease, the law of karma will ensure that society will continue to be dysfunctional and violent. Also, as society continues to treat animals and the rest of creation with cruel indifference, we will continue to bring ecological and socio-economic catastrophes upon ourselves and upon the generations to come.

As consumers we can be empowered by the doctrine of ahimsa to choose wisely and with compassion. By so doing, we help undermine the economic basis and incentives that are the primary reasons for the continuation of so much animal cruelty and suffering. As voting citizens, we can support local, state and 
federal environmental and animal protection legislation, and push for better enforcement of such laws.

\section{Developmental and Educational Considerations}

Our self-interest can be so self-centered that it leads us to have no regard for nature except as a resource: to have little or no compassion for animals and respect for the inherent value of all of Earth's creation. The evolution of species is deeply rooted in self-interest, from self-preservation to self-perpetuation. The evolutionary success of the human species is, however, turning into a scenario of tragic failure. This is in part due to the fact that our impact upon the planet has expanded globally, but this expansion has not been accompanied by a comparable expansion of our sense of self and responsibilities as a planetary species. We are the Earth, insofar as our selfhood or being is connected historically, ecologically, biologically and spiritually with the entire life community of the Earth.

This symbiotic life community, as Father Thomas Berry has proposed, is built upon a communion of subjects rather than upon a collection of objects. Within this community we find a sacrificial dimension where life gives to life in order to sustain the entire community. While we are physically, and to a degree unconsciously connected with this community, with the rocks, trees, waters, air, the food we eat, and so forth, we can become consciously connected with the life community through our ability to empathize: to put ourselves in another's place. Empathy connects and universalizes the self with the suffering, joy, wonder and mystery of all life. Without empathy, we become disconnected and relating objectively, turn the subjects of empathic communion and celebration into objects that we variously demean and exploit. In the process, we do no less to ourselves: And as we empty the cosmos of "interiority," of subjectivity, intrinsic value and significance, we do the same to ourselves and to each other.

Healthy children have a natural capacity to empathize, a capacity that parents and others must nurture. But too often this essential attribute of our humanity is crushed, if not by parents, then by the values and attitudes children acquire even in schools of learning and religious instruction.

Ethical sensibility arises naturally from empathic sensitivity. The absence of empathy means the absence of ethical sensibility, which in turn necessitates the imposition of law and order and often blind (unfeeling) obedience to moral codes. As Lao Tzu said some 3,000 years ago, "When the way of harmony (empathy) was lost, then there was morality, law, knowledge and great pretence."

In order to help ensure that this ability to empathize becomes integrated with the ethical and spiritual percepts of the community, many preindustrial civilizations carefully nurtured and educated their children, especially through example and initiation rituals. Initiation rituals were designed to reintegrate the developing sense of self (our adolescent egos) with both the "unconscious" side of our natures and with the ecos or natural world and life community around us. Unintegrated, the adolescent human ego is a terribly selfish and potentially destructive force. A fully integrated human consciousness (and conscience) is a developmental state wherein the ego self is perceived as being one with the eco- or universal self as life in life. This is the only basis for a humane, sustainable and socially just society.

When the Earth is poisoned and its ecology dysfunctional, human health and a functional society are unattainable ideals. To heal ourselves, therefore, we must heal the planet, and to heal the planet we must heal ourselves. But nothing will be well until we show respect and compassion toward our fellow creatures, otherwise injustice and inhumanity will continue to ravage every human community around the world that sees itself somehow superior to and separate from the rest of creation.

The ancient doctrine of ahimsa should be the unifying principle that links animal and environmental rights and protection with human rights and interests. No philosophy of bioethics, no Constitution, religion, industrial economy or technology, is acceptable without this unifying humane principle.

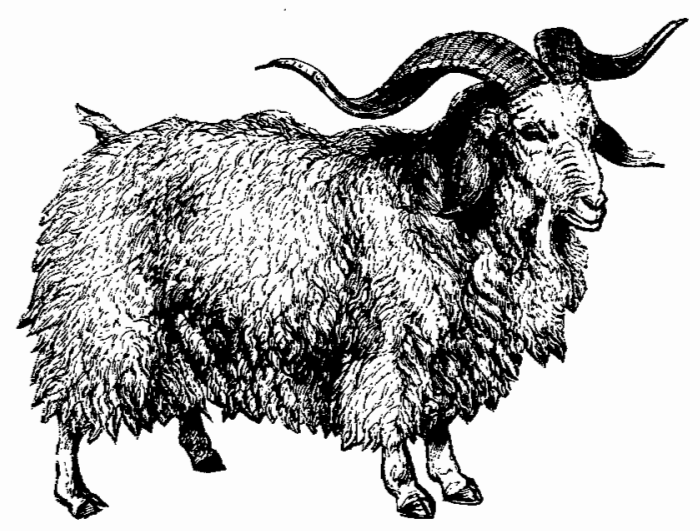

